\title{
Proteomic Analysis and Label-Free Quantification of the Large Clostridium difficile Toxins
}

\author{
Hercules Moura, ${ }^{1}$ Rebecca R. Terilli, ${ }^{1,2}$ Adrian R. Woolfitt, ${ }^{1}$ Yulanda M. Williamson, \\ Glauber Wagner, ${ }^{1,3}$ Thomas A. Blake, ${ }^{1}$ Maria I. Solano, ${ }^{1}$ and John R. Barr ${ }^{1}$ \\ ${ }^{1}$ Division of Laboratory Sciences, National Center for Environmental Health, Centers for Disease Control and Prevention (CDC), \\ MS F-50, 4770 Buford Hwy NE, Atlanta, GA 30341, USA \\ ${ }^{2}$ Association of Public Health Laboratories, Silver Spring, MD 20910, and Oak Ridge Institute for Scientific Education, Oak Ridge, \\ TN 37380, USA \\ ${ }^{3}$ Universidade do Oeste de Santa Catarina, 89600 Joacaba, SC, Brazil
}

Correspondence should be addressed to John R. Barr; JBarr@cdc.gov

Received 12 April 2013; Revised 23 June 2013; Accepted 24 June 2013

Academic Editor: Jen-Fu Chiu

Copyright (C) 2013 Hercules Moura et al. This is an open access article distributed under the Creative Commons Attribution License, which permits unrestricted use, distribution, and reproduction in any medium, provided the original work is properly cited.

Clostridium difficile is the leading cause of antibiotic-associated diarrhea in hospitals worldwide, due to hypervirulent epidemic strains with the ability to produce increased quantities of the large toxins TcdA and TcdB. Unfortunately, accurate quantification of TcdA and TcdB from different toxinotypes using small samples has not yet been reported. In the present study, we quantify C. difficile toxins in $<0.1 \mathrm{~mL}$ of culture filtrate by quantitative label-free mass spectrometry (MS) using data-independent analysis $\left(\mathrm{MS}^{\mathrm{E}}\right)$. In addition, analyses of both purified TcdA and TcdB as well as a standard culture filtrate were performed using gel-based and gel-independent proteomic platforms. Gel-based proteomic analysis was then used to generate basic information on toxin integrity and provided sequence confirmation. Gel-independent in-solution digestion of both toxins using five different proteolytic enzymes with MS analysis generated broad amino acid sequence coverage (91\% for TcdA and 95\% for TcdB). Proteomic analysis of a culture filtrate identified a total of 101 proteins, among them TcdA, TcdB, and S-layer proteins.

\section{Introduction}

Clostridium difficile is a gram-positive, anaerobic, sporeforming, rod-shaped bacterium that can produce at least three toxins including two Rho GTPase-glucosylating toxins (TcdA and TcdB) and the binary C. difficile transferase (CDT) toxin. The organism can cause C. difficile infection (CDI) in humans and animals. C. difficile is considered an important cause of healthcare-associated infection in humans and is the leading cause of antibiotic-associated diarrhea in hospitals worldwide [1, 2]. CDIs are toxin-mediated illnesses that range from mild diarrhea to fulminant pseudomembranous colitis and toxic megacolon, which may result in death [3]. Laboratorial confirmation of CDI needs to be rapidly performed. The methods include detection of $C$. difficile through cultivation, detection of Tcd A and Tcd B in stool samples using immunoassay and DNA-based methods [2].
Reflecting its changing epidemiology, the incidence and severity of CDI have increased significantly in the past ten years. Among the possible causes of increasing morbidity is the emergence of strains considered to be more virulent [4]. These strains produce greater amounts of toxin than reference strains and are highly transmissible due to their greater sporulation capacity [4]. One example is the rapid emergence of the highly virulent clone-designated BI/NAP1/027 in multiple countries [5]. Additionally, it is estimated that there are $\sim 500,000$ cases of CDI per year in US hospitals and long-term facilities alone, with an estimated $\sim 15,000$ to 30,000 deaths [2]. Since the illness may be severe and is difficult to treat and there is currently no available vaccine, preventing individual cases and outbreaks of CDI is a major challenge.

Although it has been demonstrated $[4,5]$ that strains or toxinotypes associated with outbreaks and high morbidity produce more toxin than historic, nonepidemic isolates, 
the expression levels of these toxins from different toxinotypes are not completely known. Moreover, the toxin load in clinical samples and culture supernatants has always been roughly estimated [5-8], and the accurate quantification of TcdA and TcdB using small samples has not yet been reported. Accurate quantification of toxins can be accomplished using proteomic strategies which may reveal key information applicable to TcdA and TcdB method development, detection, understanding toxic mechanisms, and production of new therapeutics including polyclonal and monoclonal antibodies [2].

Proteomics has been described as a key technology in the postgenomic era that provides information complementary to that provided by genomics. Proteins can be analyzed rapidly, accurately, and with high sensitivity using mass spectrometry (MS). Proteomic examinations have been performed for $C$. difficile in which proteins released in vitro during high toxin production [7] were identified for strains 630 and VPI 10461. Additional studies characterizing the subproteomes of $C$. difficile reference strain 630, including a surface protein and insoluble protein fraction analysis $[9,10]$, spore protein identification [11], and a protein assessment associated with heat stress responses, have also been reported [12]. In an additional study, culture supernatants of $C$. difficile reference strain 630 were compared to two hypervirulent strains (CD196 and CDR20291), and five secreted proteins were identified exclusively in the supernatants of the hypervirulent strains [13].

Absolute protein quantification by MS is a well-studied technique typically performed using stable isotope dilution [14-16]. However, applying a data-independent analysis $\left(\mathrm{MS}^{\mathrm{E}}\right)$ that does not require labeled compounds and is amenable to sample-limited experiments [17] is a newly available alternative. In $\mathrm{MS}^{\mathrm{E}}$, data are acquired in a dataindependent fashion using an alternating low/high-energy scan mass analysis and can be used to perform both protein identification and quantification in one MS experiment [18, 19].

We have previously described MS-based proteomics studies of different bacterial toxins [20], including botulinum neurotoxin [21, 22], anthrax lethal factor [20], and pertussis toxin [23]. In the present study, we describe a gel-based proteomic analysis of TcdA and TcdB. A gel-independent approach was also used in which the toxins were digested by five different proteolytic enzymes to maximize amino acid sequence coverage. Toxin digests were analyzed qualitatively using two different MS instrument platforms and were further analyzed using a label-free quantitative methodology. This study provides the performance characteristics and the basis for future development of improved MSbased detection and quantification methods for TcdA and TcdB and may help to identify protein factors involved in $C$. difficile toxin production by different isolates. We expect that such efforts will contribute to a better understanding of these toxin-mediated illnesses and will lead to new preventive measures and therapies against $C$. difficile infection.

\section{Materials and Methods}

2.1. Clostridium difficile Toxins. Purified TcdA (one lotlot 1-15215A1C) and TcdB (two lots-lot 1-1551A1B and lot $2-15518 \mathrm{~A} 1 \mathrm{~B})$ used in this study were purchased from List Biologicals Laboratories Inc. (Campbell, CA, USA). The toxins were purified from $C$. difficile VPI 10463-ATCC 43255 and were provided in vials containing $100 \mu \mathrm{g}$ of TcdA or $20 \mu \mathrm{g}$ of TcdB lyophilized in $0.05 \mathrm{M}$ Tris. Three vials of each toxin (TcdA lot $1, \mathrm{TcdB}$ lot 2) were assigned numbers in house and designated as distinct biological samples (BioS1, BioS2, and BioS3). The vials containing TcdA and TcdB were reconstituted as per the manufacturer's instructions, aliquoted, and used immediately as the designated BioS. Aliquots $(20 \mu \mathrm{L})$ from the first biological sample (BioS1) were used to run SDSPAGE gels and for three separated fast trypsin in-solution digestions to verify method reproducibility [24]. Ten microliters aliquots from samples designated as BioS2 were digested using five different enzymes in parallel to obtain maximum protein sequence coverage. Aliquots of BioS3 were serially diluted (1:2 factor, starting at $2 \mu \mathrm{g}$ and ending at $0.125 \mu \mathrm{g})$ and used to determine the sensitivity of the $\mathrm{MS}^{\mathrm{E}}$ method used in this study. In addition, a commercially available lyophilized C. difficile culture filtrate (CFil) control reagent (Techlab Clostridium difficile Toxin/Antitoxin Kit-T5000, Blacksburg, VA, USA) was used for both the quantitative method and qualitative proteomic analyses. A schematic flow diagram of the procedures used in this work can be found in Figure 1. All chemicals used in this study were purchased from SigmaAldrich (St.Louis, MO, USA) unless otherwise indicated.

2.2. SDS-PAGE Analysis and In-Gel Digestion. Duplicates of purified TcdA lot 1 (BioS1) and two lots of TcdB lot 1 and lot 2 (BioS1) were treated with NuPAGE (Invitrogen Carlsbad, CA, USA) sample buffer and the proteins were separated by $1 D$ SDS-PAGE using the NuPAGE Novex system (Bis-tris-gels; $4-12 \%$ polyacrylamide gradient) as per the manufacturer's instructions (Invitrogen). In addition, BioS1 in-solution tryptic digests were separated using Tricine gels (Invitrogen). The gels were then either stained with Colloidal Coomassie Blue (GelCode Blue Safe Protein Stain-Thermo Scientific, Pierce, Rockford, IL, USA) or with Pierce Silver Stain Kit for Mass Spectrometry (Thermo Scientific). After being scanned, each gel band was cut into slices of approximately $0.4 \mathrm{~cm}$. In-gel digestion was performed with sequence grade trypsin (Promega, Madison, WI, USA) as previously described [21]. Briefly, the gel slices were dried for $30 \mathrm{~min}$ using a Centrivap concentrator (Labconco, Kansas City, MO, USA) and $10 \mu \mathrm{L}$ of trypsin $(0.5 \mu \mathrm{g} / \mu \mathrm{L})$ diluted in $25 \mu \mathrm{L}$ of a $50 \mathrm{mM}$ ammonium bicarbonate solution, $\mathrm{pH} 8.5$, containing $1 \mathrm{mM}$ calcium chloride (digestion buffer), was added to each sample. After $5 \mathrm{~min}$ incubation at room temperature (RT), $25 \mu \mathrm{L}$ of digestion buffer was added and the samples were incubated at $37^{\circ} \mathrm{C}$ overnight $(\mathrm{ON})$. Following $\mathrm{ON}$ incubation, the digests were quenched with $0.1 \%$ formic acid (FA), sonicated for $3 \mathrm{~min}$, and centrifuged at $1200 \mathrm{~g}$ for $10 \mathrm{~min}$. The supernatants were used for nanoscale ultrapressure liquid chromatography (nUPLC)-MS/MS analysis. 


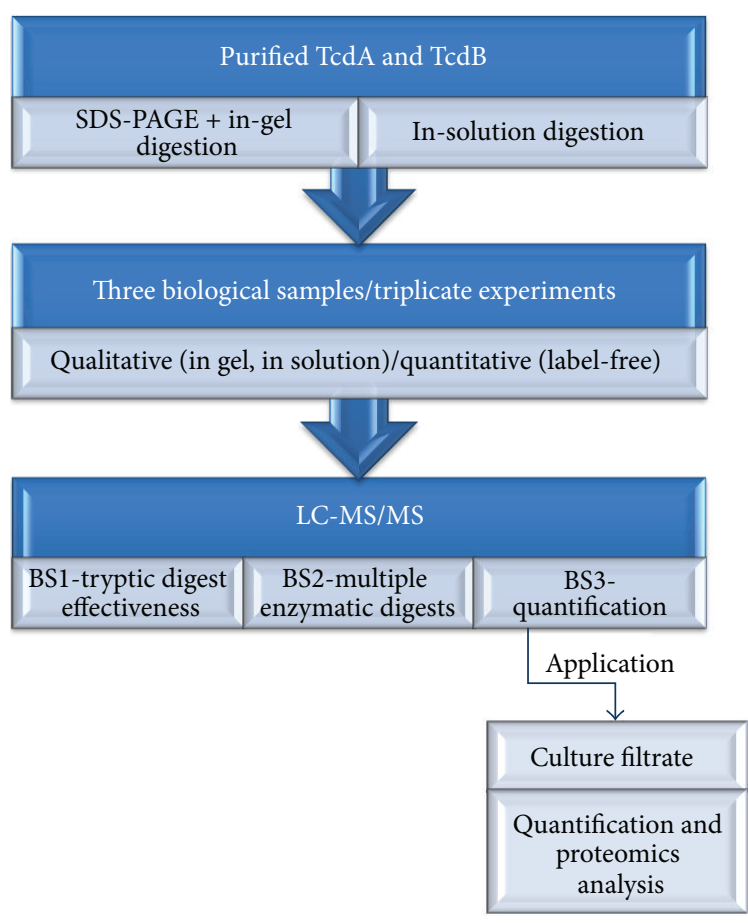

FIGURE 1: Schematic flow diagram of baseline data and biomarker discovery methods to study the large $C$. difficile toxins.

2.3. In-Solution Enzymatic Digestion. In-solution detergentbased $3 \mathrm{~min}$ tryptic digestions were performed as described [21], using three aliquots of purified TcdA (lot1) and TcdB (lot2) (BioS1, S2, and S3) $(1 \mu \mathrm{g} / \mu \mathrm{L})$ and CFil $(10 \mu \mathrm{g} / \mu \mathrm{L})$. Ten microliters of $0.2 \%$ RapiGest (RG), an acid-labile surfactant (Waters Corporation, Milford, MA, USA), in-digestion buffer, was added to each $10 \mu \mathrm{L}$-aliquot of TcdA, TcdB, and $\mathrm{CFil}$ and the tubes were incubated at $99^{\circ} \mathrm{C}$ for $5 \mathrm{~min}$ using a thermocycler (Applied Biosystems, Foster City, CA, USA). The solution was rapidly cooled to RT, and trypsin ( $~ 50 \mathrm{pmol})$ in-digestion buffer, was added. The samples were incubated at $52^{\circ} \mathrm{C}$ for $3 \mathrm{~min}$. To hydrolyze the RG, $10 \mu \mathrm{L}$ of $0.45 \mathrm{M}$ $\mathrm{HCl}$ was added and the samples were incubated at $37^{\circ} \mathrm{C}$ for $30 \mathrm{~min}$. The suspension was further diluted to a final volume of $50 \mu \mathrm{L}$ with $0.1 \%$ FA and centrifuged $(1200 \mathrm{~g})$ for $10 \mathrm{~min}$. The supernatant containing the peptides was frozen at $-70^{\circ} \mathrm{C}$ if not used immediately. For calibration of the quantification method, yeast alcohol dehydrogenase (ADH) standard tryptic digest solution (Waters Corporation) was added to the supernatant before analysis by $\mathrm{MS}^{\mathrm{E}}$, at a concentration required to give $100 \mathrm{fMol} \mathrm{ADH}$ on column. Each toxin was digested in triplicate (technical replicates) and submitted to the MS instrument in triplicates (analytical replicates) and the results of all MS runs were compared. To visually evaluate digestion effectiveness, BioS1 tryptic digests were analyzed using SDS-PAGE tricine gels and silver stained. Four additional enzymes, AspN, chymotrypsin, GluC, and LysC (Sigma-Aldrich, San Louis, MO, USA), were separately used to digest aliquots of BioS2 in order to maximize proteome coverage. Enzymatic digestions were performed as per the manufacturer's instructions.
2.4. MS Analyses and Database Search. Liquid chromatography-tandem mass spectrometry (LC-MS/MS) was carried out using an nUPLC coupled either to a QTof Premier MS system (Waters Corporation, Milford, MA, USA), or to a linear ion trap (LTQ)-Velos Orbitrap tandem MS instrument (Thermo Scientific, San Jose, CA, USA). All the conditions for nUPLC separation, (including flow rate and solvent concentrations) as well as the $\mathrm{MS}^{\mathrm{E}}$ method on the QTof Premier MS, were used as previously described [21].

Each digest was analyzed in triplicate (three analytical replicates per digest sample), and the respective raw data files obtained using data-independent $\mathrm{LC}-\mathrm{MS}^{\mathrm{E}}$ were further processed using the ProteinLynx Global Server v2.4 software (PLGS, Waters Corporation), for protein identification and quantification. Database searches were performed using the PLGS Identity ${ }^{\mathrm{E}}$ database search algorithm against either a UniProt protein database (November 2009; $6 \times 10^{5}$ entries) or a modified NCBInr database created with the term "difficile" (December 2010; $3.5 \times 10^{3}$ entries) to which the ADH 30,030 Da amino acid sequence was added. The PLGS software package provided statistically validated peptide and protein identification along with the determination of the stoichiometry of the protein constituents of the mixture (relative quantification) along with the expected amounts of protein present in the mixture (absolute quantification). The remaining parameters, including mass accuracy for precursor $(10 \mathrm{ppm})$ and product $(20 \mathrm{ppm})$ ions and criteria for protein identifications, were defined as before [21]. Similarly, relative protein quantification for the ADH digest-spiked samples (100 fMol on the column) was obtained using both the PLGS Identity ${ }^{\mathrm{E}}$ and the Expression software $[18,19]$. The clustered dataset was exported from PLGS and further analyzed with Microsoft Excel 2010 (Microsoft Corporation, Redmond, WA, USA). Scaffold (v3.01, Proteome Software Inc., Portland, OR, USA) was used to further validate MS/MS based peptide and protein identifications as before [21]. The reported data represent three technical replicates and three analytical replicates.

Additionally, protein digests were analyzed using an LTQ Velos Orbitrap tandem MS instrument. Peptides were separated using an nUPLC system directly coupled online to the MS instrument through an Advance Captive Spray source from Michrom Bioresources (Auburn, CA, USA). The spray voltage was set at $1500 \mathrm{~V}$, and the capillary temperature was $200^{\circ} \mathrm{C}$. nUPLC separation was performed as previously described [21]. Briefly, the mobile phase consisted of (solvent A) $0.2 \% \mathrm{FA}, 0.005 \%$ trifluoroacetic acid (TFA) in water, and (solvent B) $0.2 \% \mathrm{FA}, 0.005 \% \mathrm{TFA}$ in ACN. The gradient was set at $5 \%$ B for $5 \mathrm{~min}$, followed by a ramp to $40 \%$ B over $90 \mathrm{~min}$, and then a ramp up to $95 \% \mathrm{~B}$ in $1 \mathrm{~min}$. The gradient was then held at $95 \%$ B for 5 min before returning to $5 \%$ B in $2 \mathrm{~min}$, followed by reequilibration at $5 \% \mathrm{~B}$ for $5 \mathrm{~min}$.

The MS was programmed to perform data-dependent acquisition by scanning the mass range from $\mathrm{m} / \mathrm{z} 400$ to 1400 at a nominal resolution setting of 60,000 FMHM for parent ion acquisition in the Orbitrap. Tandem mass spectra of doubly charged and higher charge state ions were acquired for the top 15 most intense ions in each survey scan. All 
tandem mass spectra were recorded by use of the linear ion trap. This process cycled continuously throughout the duration of the nUPLC gradient. All tandem mass spectra were extracted from the raw data file using Mascot Distiller (Matrix Science, London, UK; version 2.2.1.0) and searched using Mascot (version 2.2.0). Mascot was setup to search using the entire NCBInr database or a modified NCBInr database created to search " $C$. difficile" recognized proteins, or to search for C. difficile strain ATCC 43255 in which trypsin is used as the digestion agent. Mascot and Scaffold search parameters were used as described before with stringent parameters so the probability of a wrong assignment was below $0.1 \%[22,23]$. PSORTb subcellular scores were used to predict and localize identified culture supernatant proteins (http://www.psort.org/psortb/) [24]. NCBI gi accession numbers were employed to assign functions to each of the identified proteins using KEGG identifiers http://www.genome.jp/ $\mathrm{kegg} / \mathrm{kegg} 3 . \mathrm{html}$ as described before [23].

\section{Results}

3.1. Gel-Based Proteomics Platform. 1D SDS-PAGE followed by silver stain revealed intense bands corresponding to purified $\mathrm{Tcd} A$ and $\mathrm{TcdB}$ proteins (Figure 2(a)). Interestingly, in the lane containing $\mathrm{TcdB}$ (lot 1), an extra, prominent band was present at the $\sim 210 \mathrm{kDa}$ MW region. However, analysis of TcdB (lot 2) revealed only one band at $\sim 270 \mathrm{kDa}$, as expected. Trypsin digestion and MS analysis of all the protein-extracted gel bands confirmed their amino acid (AA) sequences as TcdA and TcdB. It also indicated that the extraband in lot 1 represents a truncated $\mathrm{TcdB}$, in which peptides corresponding to AA 1 through 543 are missing. This finding can be observed in Figure 2(b) through the analysis of the matched peptides detected after overlaying the amino acid sequences detected in the two excised gel bands from lot 1 .

3.2. Gel-Independent Proteomics Platform. First, three separate aliquots of BioS1 (TcdA lot1 and TcdB lot2) were used to verify the effectiveness of the $3 \mathrm{~min}$ digestion method for the large $C$. difficile toxins. As revealed by nUPLCMS/MS analysis, in-solution digestion of the toxins generated a large peptide pool. Additionally, to confirm completeness of digestion, analysis of the digests using a silver-stained Tricine gel (not shown) revealed no bands, suggesting completeness of digestion.

Secondly, BioS2 aliquots were digested in parallel using multiple enzymes. The amino acid percent coverage, for TcdA and TcdB for each enzyme used, was 37\% and 34\% for AspN, $28 \%$ and $35 \%$ for chymotrypsin, $40 \%$ and $61 \%$ for GluC, $8 \%$ and $57 \%$ for LysC, and $80 \%$ and $66 \%$ for trypsin. The two enzymes that delivered the most complementary sequence coverage were trypsin and GluC (combined sequence coverage of $83 \%$ for TcdA and $86 \%$ for TcdB). Summation of the entire MS peptide analysis revealed broad amino acid sequence coverage for $\mathrm{Tcd} A(91 \%)$ and $\mathrm{TcdB}(95 \%)$.

Finally, BioS3 was used for the absolute quantification of TcdA and TcdB in small samples using $\mathrm{MS}^{\mathrm{E}}$ (Table 1). The minimum amounts of digested TcdA and TcdB in buffer that can be loaded on the nUPLC column and still be detected were, respectively, $5 \mathrm{ng}(1.6 \mu \mathrm{g} / \mathrm{mL})$ and $1.25 \mathrm{ng}(0.43 \mu \mathrm{g} / \mathrm{mL})$.

A further application of the $\mathrm{MS}^{\mathrm{E}}$ method was to successfully determine the relative and absolute amounts of TcdA and $\mathrm{TcdB}$ in a commercial lyophilized $C$. difficile culture filtrate (CFil) control reagent. In addition, because $\mathrm{MS}^{\mathrm{E}}$ data analysis can be used to determine the relative abundance of proteins in a complex mixture, data obtained with the CFil were processed and 24 constituents of the filtrate could be quantified (Table 2). Data analysis clearly shows that the S-layer proteins were the most abundant proteins in the mixture, followed by TcdA and TcdB. After proteomic analysis of the CFil using both MS instruments, a total of 101 proteins were identified. With the stringent parameters used for Peptide Prophet and Protein Prophet within the Scaffold software, the false discovery rate was zero. Psort and KEGG localization disclosed that most proteins (72\%) were cytoplasmatic (Figure 3).

\section{Discussion}

The large toxins $\mathrm{TcdA}$ and $\mathrm{TcdB}$ are the major virulence factors of Clostridium difficile and are primary markers for diagnosis of CDI. These toxins are glycosyltransferases involved in the inactivation of small GTPases which is a key factor in disease pathogenesis. The present proteomic study is foundational and is aimed at exploring the potential of this methodology for the development of a mass spectrometry-based method for accurate TcdA and TcdB quantification. Gel-based 1D SDS-PAGE analysis of TcdA and $\mathrm{TcdB}$ was performed, followed by in-gel trypsin digestion of the proteins and further mass spectrometric analysis. A gelindependent approach was also performed using in-solution multienzymatic digestion of TcdA and TcdB followed by nUPLC-MS/MS, with both data-dependent analysis and LC-MS ${ }^{\mathrm{E}}$. Data-independent analysis is advantageous as it can potentially provide both absolute and relative label-free quantification results.

The gel-based approach provided critical information on $\mathrm{TcdA}$ and $\mathrm{TcdB}$ protein integrity and amino acid (AA) sequence coverage maps. The expected unique protein band $(\sim 300 \mathrm{kDa} \mathrm{MW})$ was visible in the TcdA lane, while two bands were observed in the TcdB lane for the first lot of a commercially available toxin. Further MS analysis of the gelexcised tryptic-digested proteins from this first lot demonstrated that the band at the $\sim 270 \mathrm{kDa}$ region was the complete $\mathrm{TcdB}$, whereas the extra-band $(\sim 210 \mathrm{kDa})$ was a truncated $\mathrm{TcdB}$ protein missing the $\mathrm{N}$-terminal peptides $(\sim 68 \mathrm{kDa})$ which are associated with enzymatic activity. Interestingly, the presence of two bands at $\sim 210$ and $\sim 68 \mathrm{kDa}$ is normally expected when $\mathrm{TcdB}$ is autocleaved by the cysteine-protease present in the toxin molecule during the activation process which can occur in vivo or in vitro $[1,2]$. However, in this case, it is possible that self-cleavage did occur and the $68 \mathrm{kDa}$ portion was lost during the manufacturer's purification process since no band for the $\mathrm{N}$-terminal fragment was observed. Fortunately, analysis of a second lot of TcdB from the same 


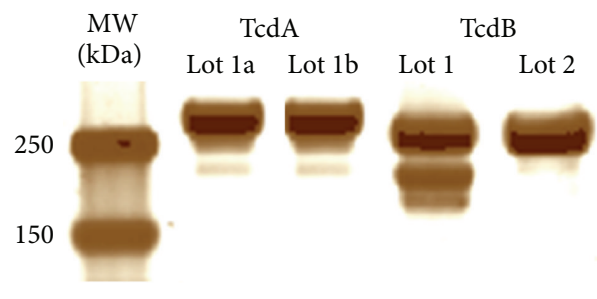

(a)

TcdA

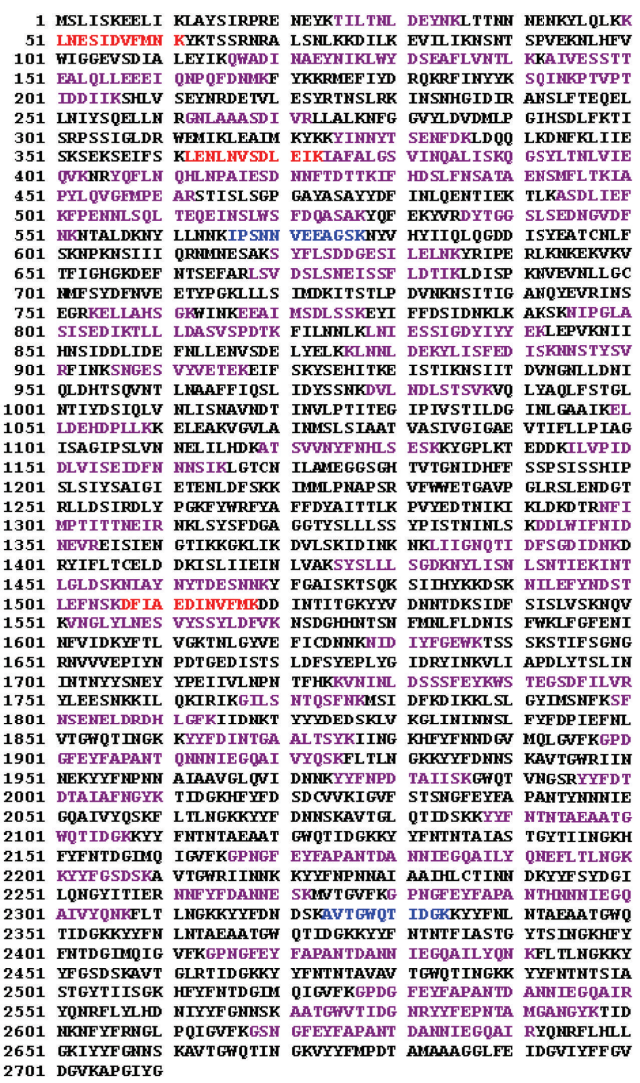

$\mathrm{TcdB}$

1 MSLVMRKQLE KMANVRFRTQ EDEYVAILDA LEEYHMMSEN TVVEKYLKL 51 DIYSITDIYI DTYKKSGRHK ALKKFKEYLV TEVLELKMHN LTPVEKHLHF 101 VWIGGQIHDT AINYIMQWKD VISSDYHVHVF YDSHAFLINT LKKTVVESAI 151 HDTLESFREY LKDPRFDYHK FFRKRMEIIY DKQKHFINYY KAQREEMPEL 201 IIDDIVKTYL SHEYSKEIDE LNTYIEESLN KITQHSGIDV RHFEEFKHGE 251 SFHLYEQELV ERWHLAAAASD ILRISALKEI GGMYLDVDM PGIQPDLFES 351 ASKSDKSEIF SSLGDMEASP LEVKIAFHSK GIIHQGLISV KDSYCSHLIV 401 KQIEKRYKIL HISLAPPAISE DHDFYTTTHT FIDS IMAEAY ADHGRFMMEL 451 GKYLRVGFFP DVKTTIHLSG PEAYAAAYYD LLMFKEGSHA IHLIEADLRM 501 FEISKTHISQ STEQEMASLW SFDDARAKAQ FEEYKRAYFE GSIGEDDHLD S01

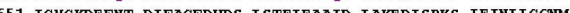
651 IGHGKDEFNT DIFAGFDVDS LSTEIEAAID LAKEDISPKS IETHLLGCMM 751 RRELIDHSGE WTHKEESIIK DISSKEYISF YPKE HKITVK SKRLPELSTL 801 LOEIRHYSHS SDIELEEKVM LTECE INVIS HIDTOIVEER IEEAKHLTSD 851 SIHYIKDEFK LIESISDALC DLKQQHELED SHFISFEDIS ETDEGFSTRF 901 INKETGESIF VETEKTIFSE YAHHTTEEIS KIRGTIFDTV HGKLVKKVNL 951 DTTHEVHTLY AAFFIQSLIE YHSSKESLSH LSVAMKVQVY AQLFSTGLRT 1001 ITDAAKVVEL VSTALDETID LLPTLSEGLP IIATIIDGVS LGAAIKELSE 1051 TSDPLLRQE I EAKIGIMAVN LTTATTAITT SSLGIASGFS ILLVPLAGIS 1101 AGIPSLVHHE LVLRDKATKV VDYFKHVSLV ETEGVFTLLD DKMMPPQDDL 1151 VISE IDFHUY SIVLGKCE IW RMEGGSGHTV TDDIDHFFSA PSITYPEPHL 1201 SIYDVLEVQK EELDLSKDLM VLPHAPHRVF AWETGWTPGL RSLEHDGTKL 1251 LDRIRDHYEG EFYWRYFAFI ADALITTLKP RYEDTHIRIN LDSHTRSFIV 1301 PIITTEYTE KLSYSFYGSG GTYALSLSQY MMGIHIELSE SDWWI IDVDH 101 1401 FVSLTFSILE GINAIIEVDL LSKSYKLIIS GELKILMINS HHIQQKIDYI 1501 DSKPSFGYYS HYLKDVKVIT KDHWHILTGY YLKDDIKISL SLTLODEKTI

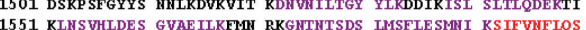
1551 KLHS VHLDES GVAE ILKFHA RKGHTHTSDS LMSFLESHEI KSIFVHFIQS 1601 HIKFILDANF IISGTTSIGQ FEFICDENDH IQPYFIKFNT LETHYTLYVG 1701 EIHITPVYET HHTYPEVIVL DANYIHEKIY VHIHDLSIRY VWSHDGHDFI 1751 LMSTSEEHKV SQVKIRFVIV FKDKTLANKL SFHFSDKQDV PVSEIILSFT 1801 PSYYEDGLIG YDLGLVSLYH EKFYIHHFGM MVSGLIYIHD SLYYFKPPVA 1851 HLITGFVTVG DDKYYFHPIM GGAASIGETI IDDKHYYFHQ SGVLQTGVFS 1901 TEDGFKYFAP ARTLDEHLEG EAIDFTGKLI IDEHIYYFDD HYRGAVEGKE 1951 LDGEMHYFSP ETGKAFKGLK QIGDYKYYFY SDGVMQKGFV SIMDHKHYFD 001 DSGVMKVGYT EIDGKHFYFA ENGEMQIGWF HTEDGFKYFA HHREDLGNEE 2051 GEEISYSGIL HFWHKIYYFD DSFTAVVGWK DLEDGSKYYF DEDTAEAYIG 151 IDI 2011 TGEIVEO 2201 FGETYTIETG WTYDHEHESD KYYFHPETKK ACKGIHLIDD IKYYFDEKG I 2301 GFXYFAHOHT IDEHFEGESI WYTGITDDE KRYYFTDEYI AATGSVIDG 2351 EEYYFDPDTA OLVISE

(b)

FIgure 2: Gel-based analysis of purified C. difficile toxins. (a) SDS-PAGE of purified TcdA and TcdB. Only one band was observed in the TcdA lanes; two bands were observed in the TcdB lot 1 lane; one band was observed in the TcdB lot 2 lane as expected. (b) Amino acid sequence coverage obtained for the two lots of $C$. difficile toxins. The gel bands were extracted, digested, and MS analyzed. Peptide sequences detected were overlaid. Sequences in Red = peptides from run la $(\mathrm{TcdA})$ or band $1(\mathrm{TcdB})$; Blue = peptides from run $1 \mathrm{~b}$ or band 2; Purple = common peptides; Black = not detected.

vendor only revealed the expected $\sim 270 \mathrm{kDa}$ band, and this lot was used in all further experiments.

The gel-independent approach provided unique information related to toxin quantification of small samples $(<0.1 \mathrm{~mL})$. The first set of experiments using BioS1 confirmed the robustness and efficiency of our modified rapid trypsin digestion method [21]. While trypsin provided sufficient AA sequence coverage to unambiguously identify TcdA and $\mathrm{TcdB}$, using one enzyme may not provide enough AA sequence information to differentiate toxins produced by different $C$. difficile strains. The use of multiple proteases has been reported before not only to improve AA coverage, but also to differentiate homologous proteins, detect posttranslational modifications, and identify editing events [25-27]. For initial discovery work, five different enzymes were used to obtain broad $C$. difficile AA coverage. However, since high-quality proteases are expensive, the use of multiple enzymes for each sample can be cost prohibitive. Working towards this, careful analysis of TcdA and TcdB AA sequence coverage maps from all five enzymes proved that using only two enzymes, trypsin and GluC, collectively garnered enough sequence information for most of our applications.

Quantification of TcdA and TcdB in samples irrespective of the volume capacity has typically been performed using enzyme-linked immunosorbent assays (ELISA) [4-8], cytotoxity assays [8, 28, 29], PCR [30], and gel densitometry [6]. 
TABLE 1: Absolute quantification of TcdA and TcdB in small samples using $\mathrm{MS}^{\mathrm{E}}$.

\begin{tabular}{|c|c|c|c|c|c|c|}
\hline \multirow[b]{2}{*}{ Digested (ng) ${ }^{*}$} & \multicolumn{6}{|c|}{ Amounts of TcdA and TcdB studied (ng) } \\
\hline & 63 & 125 & 250 & 500 & 1,000 & 2,000 \\
\hline Expected $(\mathrm{ng})^{* *}$ & 1.25 & 2.5 & 5 & 10 & 20 & 40 \\
\hline \multicolumn{7}{|l|}{ TcdA } \\
\hline $\operatorname{Expl}^{* * *}$ & 0 & 0 & 3.08 & 8.7 & 16.46 & 31.7 \\
\hline Exp2 & 0 & 0 & 3.2 & 6.5 & 18.4 & 30.2 \\
\hline Exp3 & 0 & 0 & 3.4 & 6.3 & 16.3 & 32.7 \\
\hline Average & 0 & 0 & 3.23 & 7.17 & 17.05 & 31.53 \\
\hline Stdev & 0 & 0 & 0.16 & 1.33 & 1.17 & 1.26 \\
\hline \multicolumn{7}{|l|}{$\mathrm{TcdB}$} \\
\hline $\operatorname{Exp}^{* * *}$ & 0.84 & 1.1 & 2.05 & 7.9 & 14.1 & 36.05 \\
\hline Exp2 & 0.83 & 1.1 & 2.5 & 4.6 & 13.04 & 33.4 \\
\hline Exp3 & 0.83 & 1.2 & 3.4 & 4.6 & 13.7 & 26.4 \\
\hline Average & 0.83 & 2.23 & 2.65 & 5.7 & 13.61 & 31.95 \\
\hline Stdev & 0.01 & 0.06 & 0.69 & 1.91 & 0.54 & 4.99 \\
\hline
\end{tabular}

Three samples each of purified toxin were serially diluted by a factor of 2 and digested with trypsin.

Each sample was analyzed three times using MSE. The numbers represent the amounts of toxin digested and the obtained values.

The minimum amounts of digested TcdA and TcdB in buffer that can be loaded on the nUPLC column and still detected were respectively $5 \mathrm{ng}(1.6 \mu \mathrm{g} / \mathrm{mL})$ and $1.25 \mathrm{ng}(0.43 \mu \mathrm{g} / \mathrm{mL})$.

${ }^{*}$ Values were estimated from the theoretical concentration based on values provided by the manufacturer.

** Amounts expected on column based on values provided by the manufacturer.

${ }^{* * *}$ Experimental values on column.

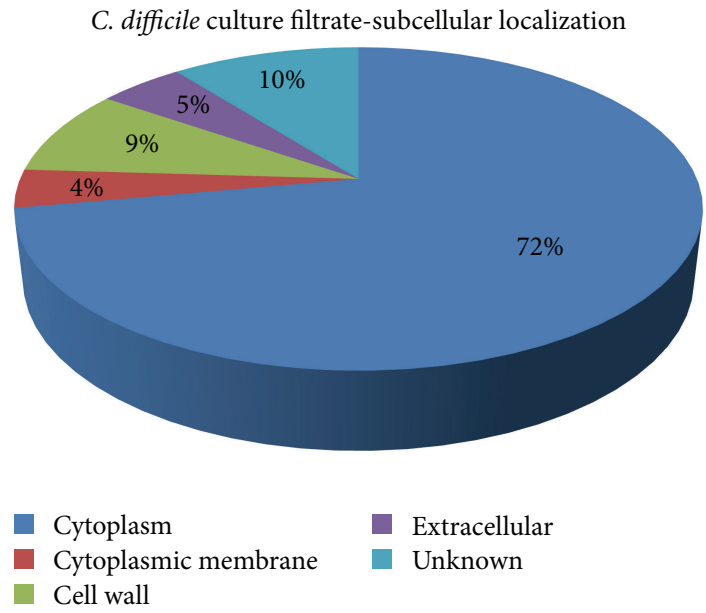

Figure 3: Subcellular localization of C. difficile proteins identified in a commercial culture filtrate using Psort score. Most proteins were cytoplasmatic (72\%).

These methods are limited in that they generally measure total toxin and do not discriminate between TcdA and TcdB.

We report here the use of data-independent nUPLC$\mathrm{MS}^{\mathrm{E}}$ to separately quantify $C$. difficile toxins in small sample volumes. After assessing the $\mathrm{MS}^{\mathrm{E}}$ spectrum data, standard curves were constructed for TcdA and TcdB, and the minimum amounts detected were determined for each toxin.

A review of $\mathrm{MS}^{\mathrm{E}}$ concepts and applications has been published by others $[18,19]$. In addition, a recent systematic evaluation of the $\mathrm{MS}^{\mathrm{E}}$ method has been reported. The authors found that there is a linear dynamic range of three orders of magnitude and low limit of quantification when they tested complex mixtures in small volumes [31]. Since the nUPLC$\mathrm{MS}^{\mathrm{E}}$ methodology is expected to be very sensitive [31], the obtained values reported in the present work for both toxins may not be ideal for samples containing small amounts of toxin. Therefore, our current research focuses on improving the sensitivity of our nUPLC-MS ${ }^{\mathrm{E}}$ method, coupling it with other known toxin concentration methods such as antibody capture prior to MS analysis [20].

Previously, we have used nUPLC-MS ${ }^{\mathrm{E}}$ for the quantification of botulinum toxin complexes [21,22]. These findings taken with the successful quantification of purified $C$. difficile large toxins reported here led us to examine a commercial culture filtrate (CFil) to determine nUPLC-MS ${ }^{\mathrm{E}}$ utility for analysis of a complex $C$. difficile mixture. A proteomic analysis of CFil, normally used as a positive control in toxicity assays, revealed the identification of 101 unique $C$. difficile proteins, of which 24 could be quantified by $\mathrm{MS}^{\mathrm{E}}$. The proteins identified are comparable with results from previous $C$. difficile proteomic studies [13]. Most importantly, proteomic quantitative analysis of a culture filtrate demonstrated the potential of these methods for further studies.

Interestingly, label-free quantification of CFil identified four proteins (S-layer protein, TcdA, TcdB, and NAD-specific glutamate dehydrogenase) all detected in significantly large amounts. One possible explanation is that these proteins are traditionally abundant and thus would likely be detected in greater amounts. In addition, they are large proteins, which once digested likely have a larger peptide pool compared to other less abundant proteins, resulting in a greater chance for detection by nUPLC-MS ${ }^{\mathrm{E}}$. Even more, other proteins, such as glycine cleavage system protein $\mathrm{H}$, isocaprenoylCoA:2-hydroxyisocaproate CoA-transferase, and molecular chaperone DnaK, that have not been previously cited in proteomic studies were also detected in lower but significant 


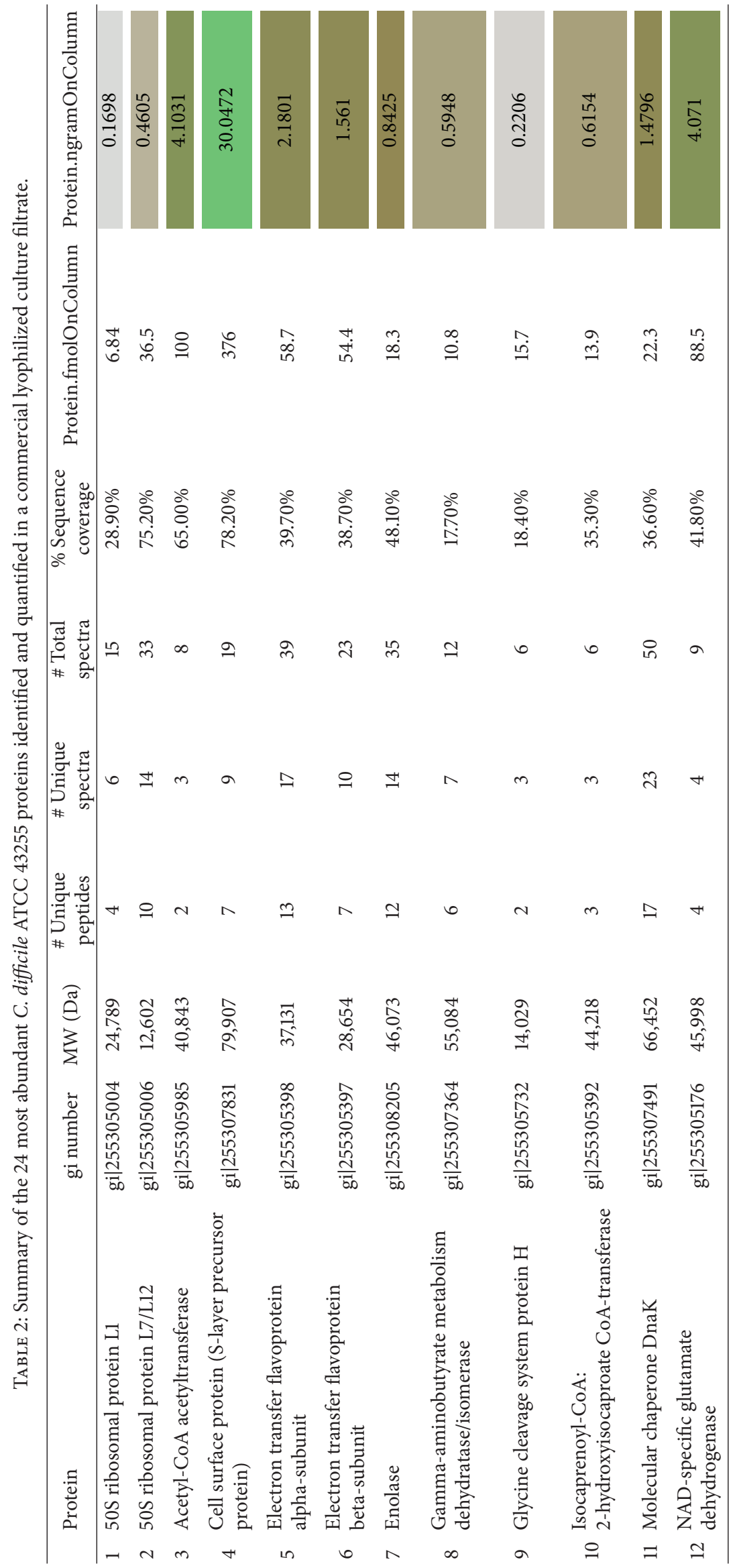




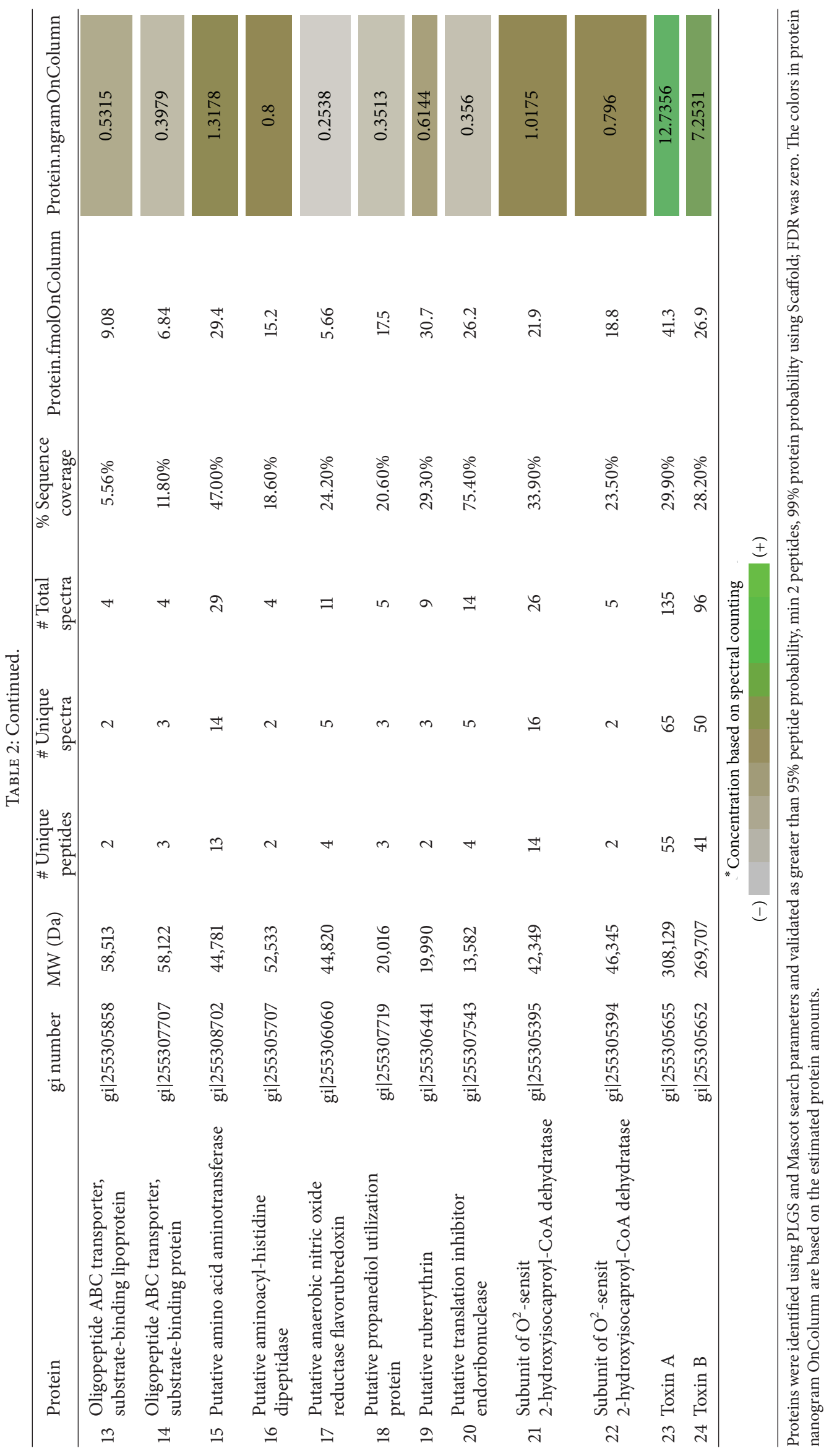


amounts. This finding suggests that culture supernatants may harbor a pool of specific proteins and could be a key matrix to search for potential unique $C$. difficile biomarkers. Because of the high TcdA and TcdB toxin concentration detected in the CFil, we initially hypothesized that the filtrate had been enriched by the manufacturer. However, we were assured by the manufacturer that the CFil used in these studies is indeed a filtrate of the culture supernatant of the strain VPI 10463, ATCC43255, which has not undergone any type of enhancement treatment, besides filtration, that would concentrate the protein pool present in this matrix (personal communication). Interestingly, a recent publication describes the proteome examination of culture supernatants of three C. difficile strains, two of them hypervirulent isolates [13]. The authors used gel-based analysis followed by MS and identified 5 unique proteins among the hypervirulent strains. They emphasized the usefulness of proteomics to discover and quantify specific biomarkers for hypervirulent strains since at least 234 unique genes have been identified in the strains that cause the majority of hospital outbreaks in North America and Europe [32].

\section{Conclusions}

Proteomic analyses using gel-based and gel-independent platforms were used to further characterize and quantitate the large $C$. difficile toxins. The overall goal was to determine the potential of proteomics using mass spectrometry-based methods to develop a quantification method for these large toxins. Moreover, the use of $\mathrm{MS}^{\mathrm{E}}$ for $C$. difficile toxin quantification in small samples, and for multienzymatic digestion to increase protein amino acid sequence coverage, was performed. The gel-based work revealed basic information on toxin integrity and provided sequence confirmation. The gelindependent platform was applied to in-solution digestion of both toxins using five different enzymes followed by analysis using two different mass spectrometer instruments. Broad amino acid sequence coverage for TcdA (91\%) and for TcdB (95\%) was generated using this approach. These data, if coupled to in silico sequencing analysis, suggest that the method has the potential to determine subtle sequence differences of $\mathrm{TcdA}$ and $\mathrm{TcdB}$ from different $C$. difficile toxinotypes. Moreover, label-free proteomics using $\mathrm{MS}^{\mathrm{E}}$ data collection and analysis provided the ability potential to determine the absolute quantity of TcdA and TcdB in small samples and was applied to a culture filtrate. A proteomic study of the culture filtrate demonstrated that the most abundant proteins are S-layer protein, TcdA, TcdB, and NAD-specific glutamate dehydrogenase. Taken together, data presented in this study provide performance characteristics and the basis for future development of improved MS-based detection and quantification methods in determining the factors involved in C. difficile toxin production by different isolates.

\section{Disclaimer}

References in this paper to any specific commercial products, processes, services, manufacturers, or companies do not constitute an endorsement or a recommendation by the US government or the Centers for Disease Control and Prevention (CDC). The findings and conclusions in this report are those of the authors and do not necessarily represent the views of CDC.

\section{Conflict of Interests}

The authors do not have any conflict of interests.

\section{Acknowledgment}

The authors wish to thank the members of the Biological Mass Spectrometry Laboratory at the National Center for Environmental Health, CDC, for helpful discussions.

\section{References}

[1] G. P. Carter, J. I. Rood, and D. Lyras, "The role of toxin A and toxin B in Clostridium difficile-associated disease: past and present perspectives," Gut Microbes, vol. 1, no. 1, pp. 58-64, 2010.

[2] M. Rupnik, M. H. Wilcox, and D. N. Gerding, "Clostridium difficile infection: new developments in epidemiology and pathogenesis," Nature Reviews Microbiology, vol. 7, no. 7, pp. 526-536, 2009.

[3] C. V. Gould and L. C. McDonald, "Bench-to-bedside review: Clostridium difficile colitis," Critical Care, vol. 12, no. 1, p. 203, 2008.

[4] M. Merrigan, A. Venugopal, M. Mallozzi et al., "Human hypervirulent Clostridium difficile strains exhibit increased sporulation as well as robust toxin production," Journal of Bacteriology, vol. 192, no. 19, pp. 4904-4911, 2010.

[5] M. Warny, J. Pepin, A. Fang et al., "Toxin production by an emerging strain of Clostridium difficile associated with outbreaks of severe disease in North America and Europe," Lancet, vol. 366, no. 9491, pp. 1079-1084, 2005.

[6] S. Karlsson, L. G. Burman, and T. Åkerlund, "Induction of toxins in Clostridium difficile is associated with dramatic changes of its metabolism," Microbiology, vol. 154, no. 11, pp. 3430-3436, 2008.

[7] K. Mukherjee, S. Karlsson, L. G. Burman, and T. Åkerlund, "Proteins released during high toxin production in Clostridium difficile," Microbiology, vol. 148, no. 7, pp. 2245-2253, 2002.

[8] P. Vohra and I. R. Poxton, "Comparison of toxin and spore production in clinically relevant strains of Clostridium difficile," Microbiology, vol. 157, no. 5, pp. 1343-1353, 2011.

[9] A. Wright, D. Drudy, L. Kyne, K. Brown, and N. F. Fairweather, "Immunoreactive cell wall proteins of Clostridium difficile identified by human sera," Journal of Medical Microbiology, vol. 57, no. 6, pp. 750-756, 2008.

[10] A. Wright, R. Wait, S. Begum et al., "Proteomic analysis of cell surface proteins from Clostridium difficile," Proteomics, vol. 5, no. 9, pp. 2443-2452, 2005.

[11] T. D. Lawley, N. J. Croucher, L. Yu et al., "Proteomic and genomic characterization of highly infectious Clostridium diffcile 630 spores," Journal of Bacteriology, vol. 191, no. 17, pp. 53775386, 2009.

[12] S. Jain, C. Graham, R. L. J. Graham, G. McMullan, and N. G. Ternan, "Quantitative proteomic analysis of the heat stress response in Clostridium difficile strain 630," Journal of Proteome Research, vol. 10, no. 9, pp. 3880-3890, 2011. 
[13] A. Boetzkes, K. W. Felkel, J. Zeiser, N. Jochim, I. Just, and A. Pich, "Secretome analysis of Clostridium difficile strains," Archives of Microbiology, 2012.

[14] J. R. Barr, V. L. Maggio, D. G. Patterson Jr. et al., "Isotope dilution-mass spectrometric quantification of specific proteins: model application with apolipoprotein A-I," Clinical Chemistry, vol. 42, no. 10, pp. 1676-1682, 1996.

[15] B. Domon and R. Aebersold, "Options and considerations when selecting a quantitative proteomics strategy," Nature Biotechnology, vol. 28, no. 7, pp. 710-721, 2010.

[16] S. Pan, R. Aebersold, R. Chen et al., "Mass spectrometry based targeted protein quantification: methods and applications," Journal of Proteome Research, vol. 8, no. 2, pp. 787-797, 2009.

[17] W. Zhu, J. W. Smith, and C. M. Huang, "Mass spectrometrybased label-free quantitative proteomics," Journal of Biomedicine and Biotechnology, vol. 2010, Article ID 840518, 6 pages, 2010.

[18] S. J. Geromanos, J. P. C. Vissers, J. C. Silva et al., "The detection, correlation, and comparison of peptide precursor and product ions from data independent LC-MS with data dependant LCMS/MS," Proteomics, vol. 9, no. 6, pp. 1683-1695, 2009.

[19] J. C. Silva, R. Denny, C. Dorschel et al., "Simultaneous qualitative and quantitative analysis of the Escherichia coli proteome: a sweet tale," Molecular and Cellular Proteomics, vol. 5, no. 4, pp. 589-607, 2006.

[20] A. E. Boyer, M. Gallegos-Candela, R. C. Lins et al., "Quantitative mass spectrometry for bacterial protein toxins-a sensitive, specific, high-throughput tool for detection and diagnosis," Molecules, vol. 16, no. 3, pp. 2391-2413, 2011.

[21] H. Moura, R. R. Terilli, A. R. Woolfitt et al., "Studies on botulinum neurotoxins type/C1 and mosaic/DC using Endopep-MS and proteomics," FEMS Immunology and Medical Microbiology, vol. 61, no. 3, pp. 288-300, 2011.

[22] R. R. Terilli, H. Moura, A. R. Woolfitt, J. Rees, D. M. Schieltz, and J. R. Barr, "A historical and proteomic analysis of botulinum neurotoxin type/G," BMC Microbiology, vol. 11, article 232, 2011.

[23] R. West, J. Whitmon, Y. M. Williamson et al., "A rapid method for capture and identification of immunogenic proteins in Bordetella pertussis enriched membranes fractions: a fasttrack strategy applicable to other microorganisms," Journal of Proteomics, vol. 75, no. 6, pp. 1966-1972, 2012.

[24] N. Y. Yu, J. R. Wagner, M. R. Laird et al., "PSORTb 3.0: improved protein subcellular localization prediction with refined localization subcategories and predictive capabilities for all prokaryotes," Bioinformatics, vol. 26, no. 13, pp. 1608-1615, 2010.

[25] R. G. Biringer, H. Amato, M. G. Harrington, A. N. Fonteh, J. N. Riggins, and A. F. R. Hühmer, "Enhanced sequence coverage of proteins in human cerebrospinal fluid using multiple enzymatic digestion and linear ion trap LC-MS/MS," Briefings in Functional Genomics and Proteomics, vol. 5, no. 2, pp. 144-153, 2006.

[26] F. Fischer and A. Poetsch, "Protein cleavage strategies for an improved analysis of the membrane proteome," Proteome Science, vol. 4, article 2, 2006.

[27] D. L. Swaney, C. D. Wenger, and J. J. Coon, "Value of using multiple proteases for large-scale mass spectrometry-based proteomics," Journal of Proteome Research, vol. 9, no. 3, pp. 13231329, 2010.

[28] J. E. Blake, F. Mitsikosta, and M. A. Metcalfe, "Immunological detection and cytotoxic properties of toxins from toxin Apositive, toxin B-positive Clostridium difficile variants," Journal of Medical Microbiology, vol. 53, no. 3, pp. 197-205, 2004.
[29] G. Yang, B. Zhou, J. Wang et al., "Expression of recombinant Clostridium difficile toxin A and B in Bacillus megaterium," BMC Microbiology, vol. 8, article 192, 2008.

[30] T. Åkerlund, B. Svenungsson, Å. Lagergren, and L. G. Burman, "Correlation of disease severity with fecal toxin levels in patients with Clostridium difficile-associated diarrhea and distribution of PCR ribotypes and toxin yields in vitro of corresponding isolates," Journal of Clinical Microbiology, vol. 44, no. 2, pp. 353358, 2006.

[31] Y. Levin, E. Hradetzky, and S. Bahn, "Quantification of proteins using data-independent analysis $\left(\mathrm{MS}^{\mathrm{E}}\right)$ in simple and complex samples: a systematic evaluation," Proteomics, vol. 11, no. 16, pp. 3273-3287, 2011.

[32] R. A. Stabler, M. He, L. Dawson et al., "Comparative genome and phenotypic analysis of Clostridium difficile 027 strains provides insight into the evolution of a hypervirulent bacterium," Genome Biology, vol. 10, no. 9, article R102, 2009. 

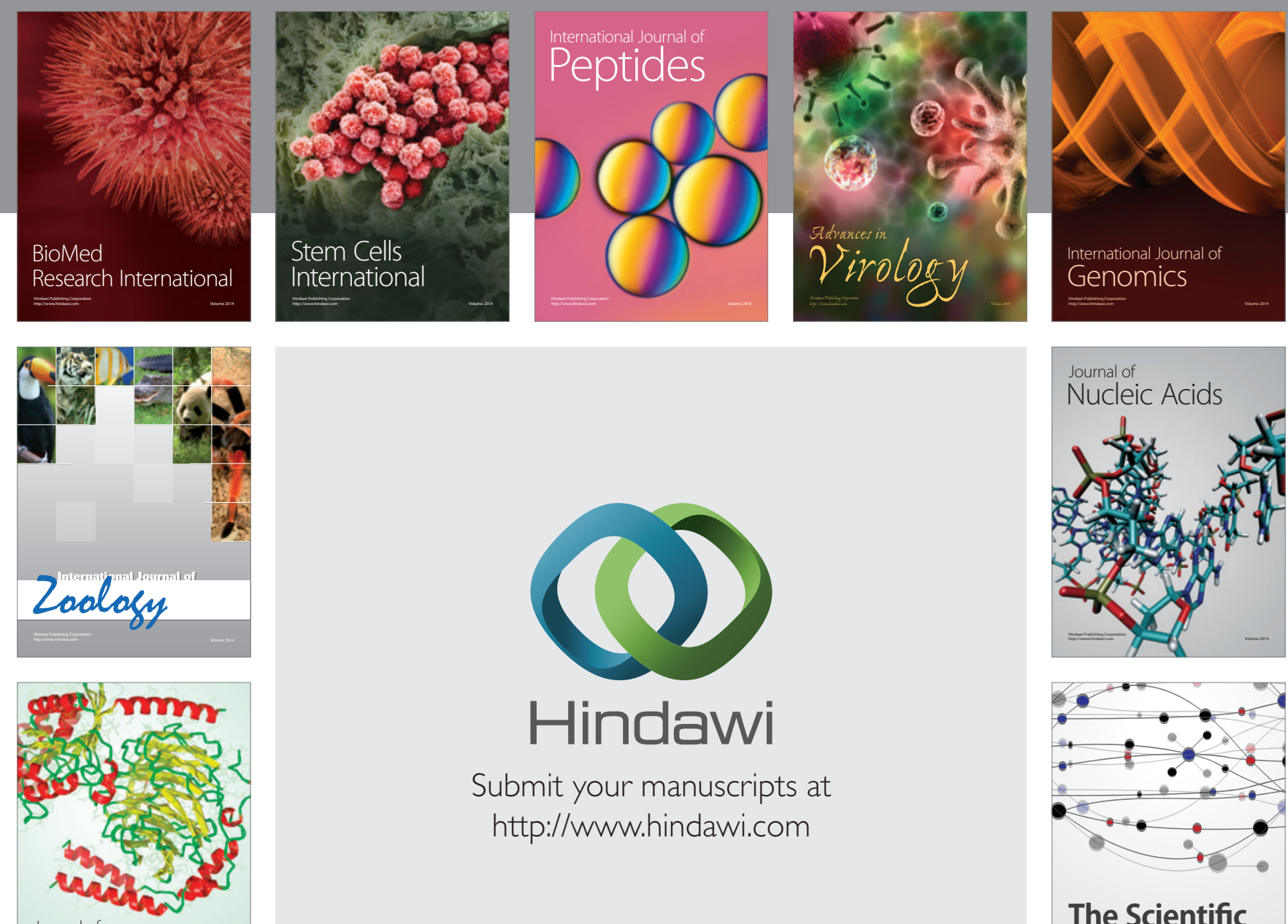

Submit your manuscripts at

http://www.hindawi.com

Journal of
Signal Transduction
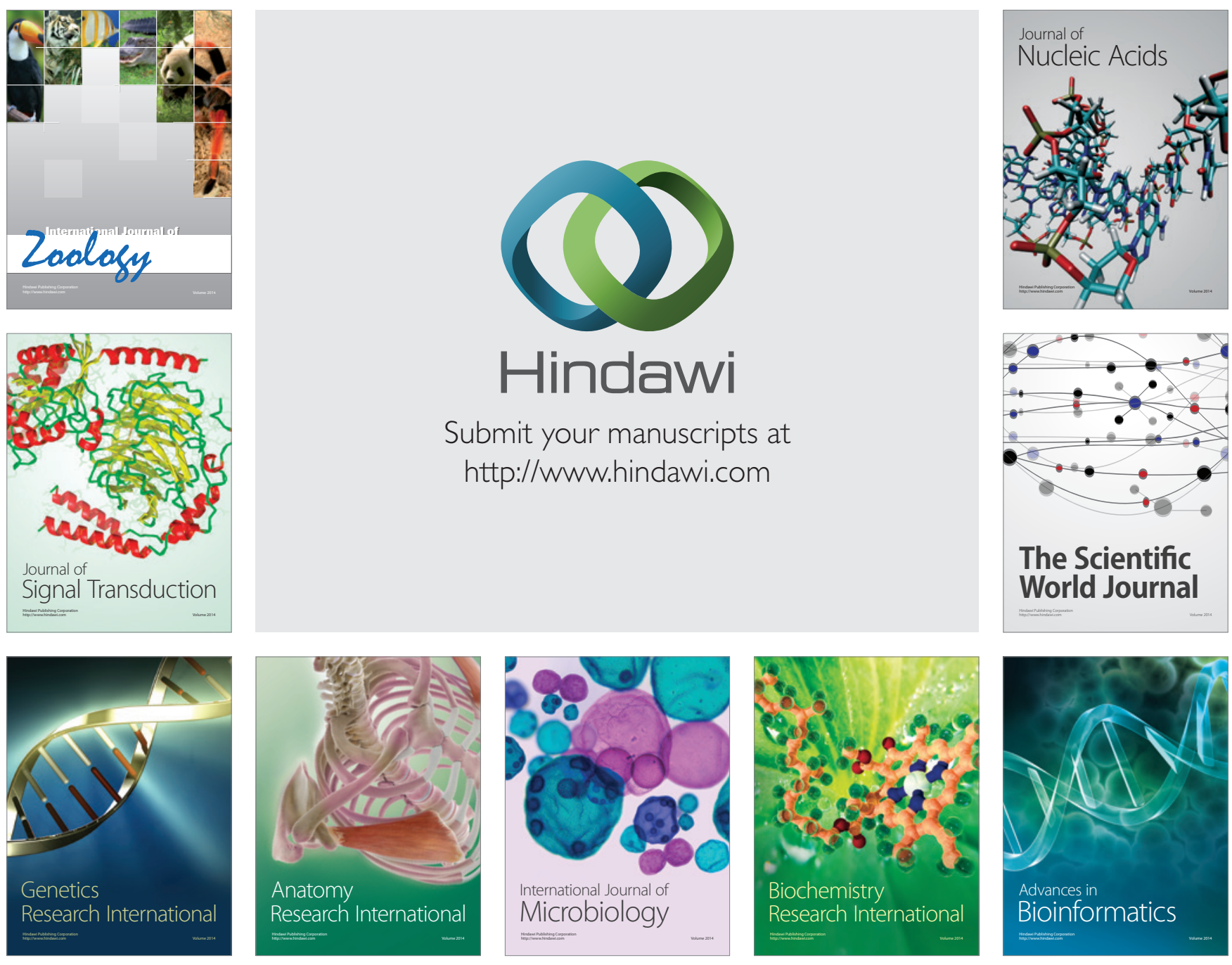

The Scientific World Journal
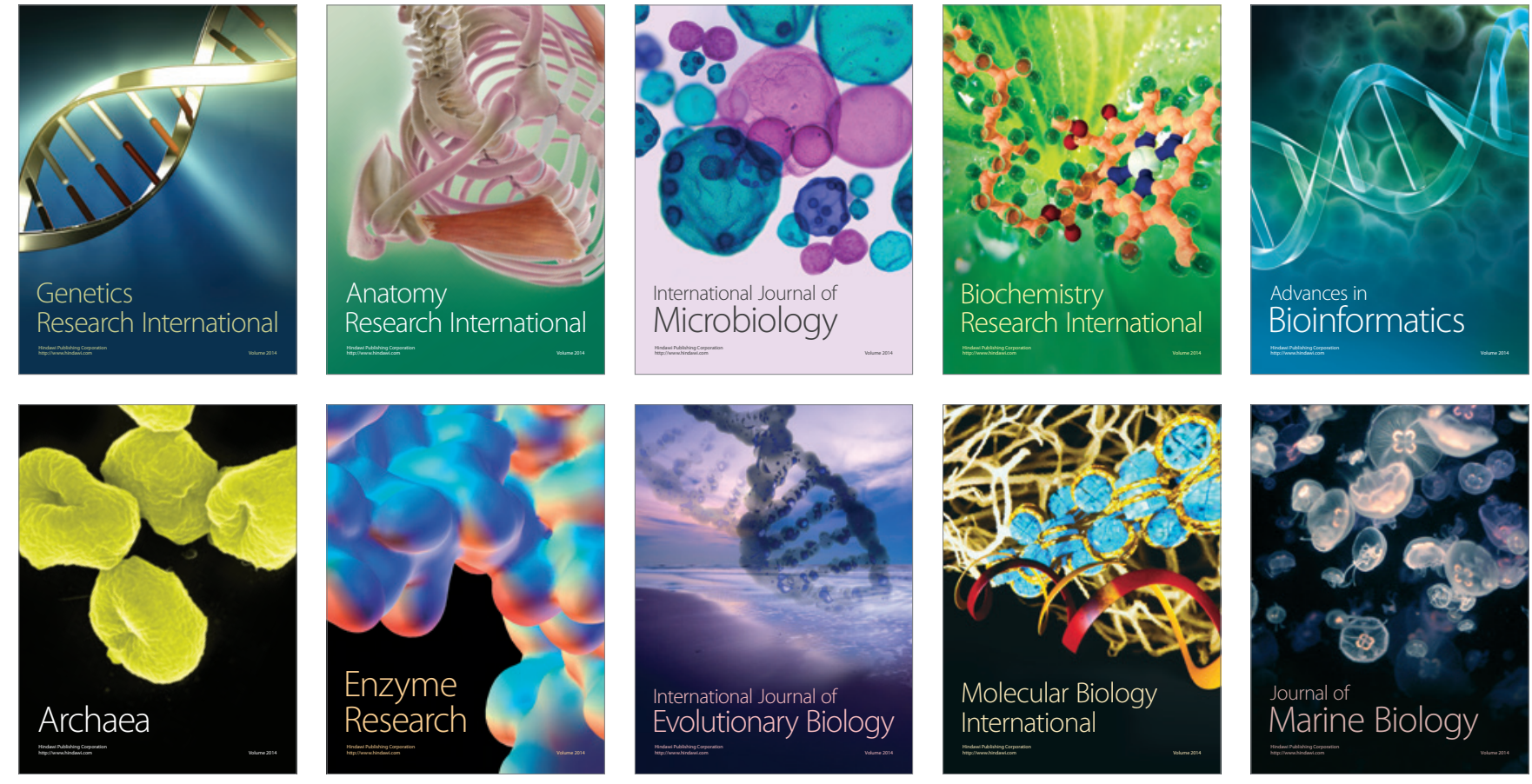